\title{
Arbitrabilidad de Actos Administrativos Contractuales
}

\author{
Francisco Santiago Larrea Naranjo*
}

Recibido/Received: 25/01/2016

Aceptado/Accepted: 19/08/2016

SUMARIO: 1. Introducción. 2. De la arbitrabilidad. 2.1 De la arbitrabilidad de los actos administrativos. 3. De la transigibilidad en el derecho administrativo. 4. De la arbitrabilidad de los actos administrativos en el derecho comparado y en el arbitraje internacional. 4.1 En el derecho comparado. 4.2 En el arbitraje internacional. 5. Conclusiones.

PALABRAS CLAVE: arbitrabilidad, acto administrativo, transigibilidad.

KEYWORDS: arbitrability, administrative acts, tradeable.

RESUMEN: En Ecuador existen normas legales que otorgan al Estado la potestad para acudir al arbitraje, lo cual nos ha llevado a analizar la arbitrabilidad de las disputas en el arbitraje administrativo, concluyendo que si existe una norma que expresamente permita al Estado acudir al arbitraje, este podrá hacerlo sin más obstáculos que los límites impuestos por la propia ley y el convenio arbitral, siendo el tribunal arbitral quien decidirá su propia competencia; sin que, por el

* Asociado senior de la firma Noboa, Peña \& Torres Abogados (Quito, Ecuador). Abogado por la Pontificia Universidad Católica del Ecuador, Especialista Superior en Derecho Financiero, Bursátil y Seguros por la Universidad Andina Simón Bolívar, Sede Ecuador, Magíster en Derecho de Empresa por la Universidad San Francisco de Quito y LL.M por Pennsylvania State University.

F. LARreA, “Arbitrabilidad de Actos Administrativos Contractuales”, Revista Ecuatoriana de Arbitraje, No. 7, 2015. 
mero hecho de que la disputa tenga que ver con normas de interés general -como sería la legalidad de los actos administrativos- sea un límite para el arbitraje. Los actos administrativos contractuales sí serían arbitrables, debido a que la arbitrabilidad de los mismos nace del ejercicio de una potestad otorgada por la ley y el único límite a su arbitrabilidad deberá encontrarse en la misma ley que establece la potestad de arbitrar o en el convenio arbitral; por lo que, los árbitros están obligados a respetar el principio de legalidad en cuanto a esta potestad de arbitrar, estando facultados a revisar su legalidad. Igualmente, esta arbitrabilidad no estaría limitada por la transigibilidad de la disputa. La transigibilidad, como límite a la autonomía de la voluntad, carece de sentido en el arbitraje administrativo.

ABSTRACT: In Ecuador there are laws that give the State the power to go to arbitration, which has led us to analyze the arbitrability of the disputes in the Administrative Arbitration, concluding that if there is a rule that specifically allows the State to arbitrate, it can do so with no more obstacles than the limits imposed by the law itself and the arbitration agreement, being the arbitral tribunal who should decide its own jurisdiction, without being a limit for arbitration the mere fact that the dispute is related to rules of general interest, as it would be the legality of Administrative Acts. Contractual Administrative Acts are, indeed, arbitrable because their arbitrability arises from the exercise of a power granted by law, and the only limit to their arbitrability should be stated in the same law that establishes the power to arbitrate, or in the arbitration agreement, so that the arbitral tribunal is obliged to respect the principle of legality in terms of this authority to arbitrate, more so it is empowered to review the legality of these Contractual Administrative Acts. Also, the tradable characteristic of a dispute cannot be taken as a limit to the arbitrability. The tradable characteristic of the dispute as a limit to the private autonomy is meaningless in the Administrative Arbitration. 


\section{INTRODUCCIÓN}

La negativa a la arbitrabilidad de los actos administrativos se ha fundamentado, principalmente, en que los actos administrativos, al ser productos del principio de legalidad con el que actúa la Administración, sumado a las presunciones de legitimidad y ejecutoriedad con las que cuentan, de los cuales se derivan algunas de las prerrogativas exorbitantes del Estado, no son transigibles y, por ende, no serían arbitrables.

Es así como, no solo en el Ecuador sino que en todos los países que adoptaron el Sistema de Derecho Administrativo del Derecho Francés, se concibió que los actos administrativos, únicamente podrían ser impugnados en sede administrativa o vía judicial ante el juez o tribunales competentes, que, en Ecuador, serían los Tribunales Distritales de lo Contencioso Administrativo.

Sin embargo, en el Ecuador, al mismo tiempo existen varias normas legales de carácter público que regulan relaciones de la Administración con particulares, en sectores sumamente importantes como son los sectores estratégicos y la contratación pública, en donde se ha establecido la posibilidad de que el Estado acuda a arbitraje; inclusive la posibilidad de pactar arbitraje en la contratación pública, ahora tiene carácter constitucional.

Esto se deriva del hecho de que en el Ecuador gran parte de la economía depende o se deriva de las relaciones contractuales que tiene el Estado, a través de sus entidades y empresas públicas, con los privados. Dentro de estas relaciones contractuales, pueden suscitarse controversias, mismas que pueden ser sometidas a arbitraje ya que el mismo se encuentra plenamente reconocido en el Ecuador, siempre que se lo haga de acuerdo con lo establecido en la ley.

La única limitación a la arbitrabilidad de disputas sometidas a arbitraje que ha establecido esta legislación, es que las mismas 
sean transigibles. Límite que es aplicable, tanto para los particulares como para el Estado.

En la actualidad existen al menos tres claras tendencias doctrinarias que se han desarrollado sobre este tema. La primera, es una tendencia que está en contra de la arbitrabilidad de los actos administrativos. La segunda, es una tendencia intermedia que se ha pronunciado a favor de la arbitrabilidad de los actos administrativos pero solo de sus efectos económicos o patrimoniales, negando la posibilidad de arbitrar la legalidad del acto administrativo. $Y$, la tercera, que es la tendencia que se ha pronunciado favorablemente para la arbitrabilidad de la legalidad de los actos administrativos, sin más límites que los mismos impuestos en la propia ley.

La problemática nace en que el concepto de transigibilidad, que es una institución del Derecho Privado, ha sido asumida por el Derecho Administrativo, sin que se haya profundizado en el análisis sobre su verdadera aplicación en el Derecho Administrativo y, sobre todo, su utilidad como límite a la arbitrabilidad cuando el Estado es parte dentro de un arbitraje.

Esta es una problemática muy interesante, ya que diferentes tribunales arbitrales, lejos de tener una posición uniforme al respecto, han optado por tomar decisiones diferentes para cada caso, creando una inseguridad jurídica, tanto para los particulares como para el mismo Estado, la cual se debe, principalmente, al hecho de que, a pesar de que la ley ha facultado al Estado a pactar arbitraje y este, efectivamente, así lo ha hecho dentro de una relación contractual, posteriormente, debido a esta interpretación de que la legalidad de los actos administrativos no son transigibles y, por ende, arbitrables, se estaría poniendo a los contratistas privados en una situación de inseguridad e indefensión ya que no se sabría, exactamente, qué parte de la disputa si podrá arbitrarse y cual no, y lo que es peor, se estaría dejando por fuera del arbitraje a disputas que las partes han consentido en someterlas a arbitraje y no a la Función Judicial, violando el convenio arbitral. 
Lo que busco en este trabajo, es establecer un criterio claro a favor de la idea de la arbitrabilidad de los actos administrativos y de la correcta aplicación (o no) del concepto de transigibilidad.

Entonces, empezaremos analizando el tema de la arbitrabilidad de manera general, para pasar inmediatamente a tratar el tema de la arbitrabilidad de los actos administrativos, tanto en Ecuador como en el Derecho Comparado y en el Arbitraje Internacional, para finalizar tratando el tema de la transigibilidad en el arbitraje administrativo.

\section{De la ARbitrabilidad}

En el arbitraje, el concepto de arbitrabilidad ha sido percibido como la condición de una disputa que la hace susceptible de ser sometida a decisión de árbitros ${ }^{1}$. Esta concepción de la arbitrabilidad nos permite identificar los límites impuestos entre la autonomía de la voluntad de las partes para pactar el sometimiento de sus controversias a arbitraje y la imperativa e ineludible jurisdicción del Estado o, como se ha dicho en algunas ocasiones, es el punto donde finaliza la autonomía de la voluntad y comienza la misión adjudicataria pública ${ }^{2}$. Esta noción se debe a que no cualquier cuestión controvertida puede ser resuelta por árbitros, siendo usual que el legislador reserve ciertos conflictos a los tribunales judiciales y no admita, que los mismos sean resueltos a través de los métodos alternativos de resolución ${ }^{3}$.

Es común y de general aceptación que, para determinar cuándo una materia es arbitrable, se recurra a los conceptos de transigibilidad o disponibilidad de los derechos ${ }^{4}$.

1. C. JARRoSSON, “L'arbitrabilité: présentation méthodologique”, Revue de Jurisprudence Commerciale, 1996, No. 1. p. 1 y ss. Citado por R. CAIvANo en La Cláusula Arbitral, 1ra. Ed., Universidad del Rosario, 2008, pp. 30-31.

2. T. Carbonneau, y F. Janson, "Cartesian logic and frontier politics: French and American concepts of arbitrability”, Tulane Journal of International and Comparative Law. vol. 2 (1), 1994, p. 193 y ss.

3. J. LEE, Arbitragem comercial internacional nos países do Mercosul, Juruá. 2002, p. 66.

4. Ibídem. 
En el Ecuador, son los artículos 190 de la Constitución de la República del Ecuador (CRE) y 1 de la Ley de Arbitraje y Mediación (LAM), son los que introdujeron este concepto de la arbitrabilidad $^{5}$ en el Ecuador.

Basándonos en estos primeros enunciados de lo que sería la arbitrabilidad, parece lógico que no toda disputa pueda ser sometida a árbitros, es por esto que la misma CRE y la LAM se han encargado de señalar que este sometimiento a arbitraje tiene que ser en materias que sean transigibles y lo deberán hacer de acuerdo con lo estipulado en la ley, otorgándole explícitamente al legislador la facultad de determinar que materias pueden o no ser arbitrables ${ }^{6}$.

No es extraño que se realice esta reserva realizada por el legislador para que sea la Función Judicial la que resuelva determinados temas dentro de ciertas áreas del derecho, que son de mayor interés para el Estado, eliminando la libertad de las partes de decidir cómo resolver las posibles controversias que puedan suceder dentro de dichas áreas. El claro ejemplo de esto es cuando se trata de derechos que exceden el interés particular de su titular, derechos de cuya tutela estarían interesados el conjunto de la sociedad, resultando lógico que se entregue la potestad de resolverlos a los jueces ordinarios.

Sin embargo, ello no implica que la única solución sea excluir tales materias de la posibilidad de ser juzgadas por árbitros. Los profesores GALLIARD y SAVAGE, señalan que existen tres posibles

5. Constitución de la República de Ecuador (CRE), RO No. 449, 20/10/2008. Art. 190.- Se reconoce el arbitraje la mediación y otros procedimientos alternativos para la solución de conflictos. Estos procedimientos se aplicarán con sujeción a la ley, en materias en las que por su naturaleza se pueda transigir. En la contratación pública procederá el arbitraje en derecho, previo pronunciamiento favorable de la Procuraduría General del Estado, conforme a las condiciones establecidas en la ley. Ley de Arbitraje y Mediación (LAM), RO No. 145, 4/09/1997. Art. 1.- El sistema arbitral es un mecanismo alternativo de solución de conflictos al cual las partes pueden someter de mutuo acuerdo, las controversias susceptibles de transacción, existentes o futuras para que sean resueltas por los tribunales de arbitraje administrado o por árbitros independientes que se conformaren para conocer dichas controversias.

6. En todo caso, lo importante puede ser como cada legislación determina los límites de la no-arbitrabilidad. E. Gaillard y J. SAVAGE (Eds.). Fouchard, GaIllard, Goldman on International Commercial Arbitration. Kluwer Law International, 1999. p. 331. Citado por R. CAIVANo. "Planteos de Inconstitucionalidad en el Arbitraje", Revista Peruana de Arbitraje, Instituto Ecuatoriano de Arbitraje, No. 2, 2006, p. 119. 
formas de asegurar que algunas materias consideradas sensibles sean resueltas en consonancia con los intereses de la sociedad: la primera consiste simplemente en prohibir el arbitraje respecto de ellas. La segunda es excluir del arbitraje aquellas cuestiones en las que una de las partes ha violado una regla de orden público. Y, la tercera, que los autores mencionados juzgan como más recomendable, es permitir a los árbitros juzgar las controversias sobre cuestiones que puede ser considerados como de orden público, sujeto al control judicial de lo decidido por aquellos ${ }^{7}$, siendo esta tercera forma la que consideramos como la idónea y más adecuada desde todo punto de vista.

Otro punto a considerar, en cuanto a la arbitrabilidad, es que las definiciones constitucionales y legales anotadas, claramente se refieren, únicamente, a la arbitrabilidad objetiva y no a la subjetiva, al mencionar que el arbitraje "[...]se aplicarán con sujeción a la ley, en materias en las que por su naturaleza se pueda transigir".

La doctrina se ha encargado de realizar una distinción entre lo que representa la arbitrabilidad subjetiva y la objetiva. La arbitrabilidad subjetiva tiene que ver con la capacidad de determinadas personas para someterse a arbitraje o lo que viene a ser lo mismo, la capacidad de los árbitros de conocer determinados casos en los cuales están inmiscuidas determinadas personas; mientras que la arbitrabilidad objetiva tiene que ver con la capacidad de los árbitros para conocer y resolver sobre determinadas materias o lo que resulta lo mismo, la capacidad de ciertas materias de ser sometidas a arbitraje.

Al tener en las definiciones mencionadas como único parámetro de arbitrabilidad a la posibilidad de transacción de una materia (arbitrabilidad objetiva), deberíamos pensar que el legislador, entonces, determinó cuales serían las materias susceptibles de transigir, sin embargo, no lo hizo.

7. Ídem, pp. 123-124. 
Esto nos lleva a remitirnos a lo señalado en el Código Civil Ecuatoriano, el cual, si bien tampoco realiza una determinación de lo que sería transigible, prefirió señalar las materias que no pueden serlo ${ }^{8}$.

Tampoco podemos concluir de esa enumeración, que esas materias sean las únicas que no pueden ser transigibles o arbitradas, existen varias materias más que resultan no arbitrables, como por ejemplo, en el Ecuador, la materia tributaria9.

Como ya lo mencionamos, ni la CRE ni la LAM han establecido restricciones subjetivas a la arbitrabilidad en las relaciones contractuales del Estado. Cualquier institución de la Administración o entidad de derecho privado con participación del Estado, puede pactar arbitraje para resolver sus disputas mediante arbitraje local o internacional, siempre y cuando se cumplan las formalidades descritas en la ley ${ }^{10}$.

8. Dentro de las que se encuentran: (i) la materia penal; (ii) el estado civil; (iii) el derecho a recibir alimentos, salvo que cuente con aprobación judicial; (iv) los derechos inexistentes o ajenos; (v) la obtenida por dolo o violencia o a propósito de un título nulo; y (vi) la materia ya resuelta en sentencia con autoridad de cosa juzgada de la cual, al tiempo de celebrarse la transacción, las partes no hubieren tenido conocimiento. Código Civil, Artículos 2351 y ss, RO Sup. No. 46. 24/06/2005.

9. Código Orgánico de la Producción, Comercio e Inversiones, Art. 27, RO Sup. No. 351, 29/12/2010. "Resolución de conflictos.- En los contratos de inversión con inversionistas extranjeros se podrán pactar cláusulas arbitrales para resolver las controversias que se presenten entre el Estado y los inversionistas. Las controversias entre un inversionista extranjero con el Estado ecuatoriano, que se hubieren agotado completamente por la vía administrativa, intentarán solucionarse de manera amistosa, con diálogos directos por un término de 60 días. Si no se llegase a una solución directa entre las partes deberá existir una instancia obligatoria de mediación dentro de los tres (3) meses siguientes a la fecha de inicio formal de las negociaciones directas. Si luego de esta instancia de mediación la controversia subsiste, el conflicto podrá ser sometido a arbitraje nacional o internacional, de conformidad con los Tratados vigentes, de los que Ecuador forma parte. Las decisiones de ese Tribunal Arbitral serán en derecho, la legislación aplicable será la ecuatoriana y los laudos serán definitivos y obligatorios para las partes. Si luego del término de 6 meses de agotada la vía administrativa, las partes no han llegado a un acuerdo amistoso, ni la hubieren sometido a jurisdicción arbitral para la solución de sus conflictos, la controversia se someterá a conocimiento de la justicia ordinaria nacional. No se someterán a arbitraje los asuntos tributarios." (las cursivas me pertenecen). Igualmente, en el contexto del arbitraje de inversiones, el Ecuador ha sostenido que los asuntos de índole tributaria no pueden ser resueltas en arbitraje. Por ejemplo, véase., LCIA, EnCana Corporation v. República del Ecuador, Laudo, Caso No. UN3481, 30/02/2006; en el que el Estado alegó que "[...]el Tribunal no es una instancia de apelación de asuntos tributarios ecuatorianos, y en la medida de que un asunto esté claramente conectado a una ley o reglamento fiscal, será claramente un tema que deba entender el Poder Judicial del Estado anfitrión.”; en J. MARChÁN, y X. ANDRADE CADENA, "El Arbitraje Comercial Internacional en Ecuador: Marco Legal y Jurisprudencial”, El Arbitraje Comercial en Iberoamérica. Marco Legal y Jurisprudencial. 1ra. Ed., 2009 , p. 328. 

ciona:

El profesor CAIVANO al tratar sobre la arbitrabilidad men-

En términos generales se define el ámbito de "lo arbitrable" diciendo que pueden someterse a decisión de árbitros aquellas cuestiones que involucran derechos "disponibles". La "disponibilidad" de un derecho es definida como la posibilidad de decidir libremente sobre él, la cualidad que lo hace susceptible, por ejemplo, de transacción y de renuncia. Más allá de la noción "normológica", desde una óptica lógica y axiológica, este razonamiento no admite dudas: si una persona puede disponer de un derecho (inclusive renunciándolo) no es posible limitar su aptitud de otorgar a un tercero, aunque no sea un juez del Estado, la potestad de determinar el contenido o el alcance de ese derecho ${ }^{11}$.

El arbitraje, desde su origen, había sido considerado como un sistema en el que solo podían resolverse conflictos que involucraran intereses exclusivamente privados. Sin embargo, la tendencia actual ha sido la de expandir, paulatinamente, la base de materias que podrían someterse a arbitraje, a pesar de que se traten de materias sensibles o de derecho público, que, antiguamente, eran reservados a los tribunales judiciales ${ }^{12}$ como pueden ser los derechos irrenunciables de las personas o, más precisamente, lo que es materia de este trabajo, la legalidad de los actos administrativos.

En principio, la concepción ha sido que los actos administrativos (incluidos los que son producto de las facultades exorbitantes de la Administración), no serían arbitrables, en cuanto a su legalidad; sin embargo, esto ha cambiado y lo sigue haciendo. Según nuestro criterio, la legalidad de los actos administrativos contractuales, así como los actos administrativos derivados del ejercicio de facultades exorbitantes y los que, en general, estén re-

\footnotetext{
10. J. MARChÁN, y X. ANDRADE, "El Arbitraje Comercial Internacional en Ecuador: Marco Legal y Jurisprudencial”, El Arbitraje Comercial en Iberoamérica. Marco Legal y Jurisprudencial, 1ra. Ed., 2009, p. 327.

11. R. Caivano, N. 6, p. 119.

12. A. GuZman, "Arbitrator liability: reconciling arbitration and mandatory rules", Duke Law Journal, Vol. 49(5), 2000. p. 1279 y ss. Citado por R. CAIVANO, N. 6, p. 358.
} 
lacionados con el contrato, sí lo serían, tal como lo revisaremos más adelante.

En este sentido, coincido plenamente con el profesor CAIVANO quien ha señalado lo siguiente:

[...] Si la jurisdicción arbitral se excluyera en la etapa inicial del proceso arbitral, por considerar que el caso involucra normas de carácter imperativo, se estaría suponiendo -sin razón alguna que lo permita- que los árbitros laudarán contra legem y que los objetivos tenidos en mira por el legislador al hacer imperativa una norma no se cumplirán si el caso es resuelto por árbitros, como sí lo sería si se resolviese por la vía judicial. Es más racional, en estos casos, dejar que los árbitros se pronuncien sobre las cuestiones que las partes le han sometido y reservar una vía de control judicial para el caso en que la decisión sea contraria a los propósitos perseguidos por el legislador. Si alguna de las partes considerara que el laudo que se dicte sobre el fondo implica dejar sin efecto o interpretar normas imperativas en un sentido incompatible con el interés público tutelado por ellas, siempre podrá plantear su nulidad o resistir su ejecución a través de los procedimientos previstos en la ley. Lo que no puede admitirse es la pretensión de excluir de antemano la jurisdicción arbitral, porque nada autoriza a las partes a suponer que los tribunales ignorarán una norma imperativa. En otras palabras, lo que eventualmente puede "violar el orden público" es lo que el Tribunal resuelva en el laudo; pero jamás la atribución de jurisdicción a los árbitros para decidir la cuestión ${ }^{13}$.

Desde nuestro punto de vista, con base en los criterios expuestos, la arbitrabilidad debe ser considerada como la regla y solo en casos excepcionales determinar la no arbitrabilidad de al-

13. R. Caivano, N. 6, p. 126. En el contexto nacional, Andrade Cevallos ha mencionado: En materia arbitral la tendencia, en los tiempos modernos, ha sido la de ampliar el marco de acción de los árbitros u en general de los medios alternativos de solución de controversias. Si la base de estos compromisos arbitrales se encuentra en la voluntad de las personas, es prudente y lógico convenir que ellas como actoras de su destino y patrimonio puedan renunciar a utilizar la justicia ordinaria y entregar a la justicia alternativa la resolución de sus conflictos aún en materias que históricamente han sido reservadas a la decisión de los órganos judiciales. M. Andrade Cevallos, "Ley de Arbitraje y Mediación. Transigible y Arbitraje en Equidad", Revista Ecuatoriana de Arbitraje, Instituto Ecuatoriano de Arbitraje, No. 4, 2012, p. 212. 
guna materia o cuestión controvertida en la cual sea evidente que los jueces de la Función Judicial serían los idóneos para resolverla y no los árbitros, siendo estos últimos quienes, con base en el principio kompetenz-kompetenz realicen esta determinación y solo por excepción que lo haga la ley.

Entonces, sí existe una norma que expresamente permite a las partes acudir al arbitraje para solucionar las disputas que surjan entre ellas, lo normal será que ellas sean aptas para hacerlo sin obstáculo alguno y que sea el tribunal arbitral quien decida su propia competencia con relación a las disputas a ellos sometidas, sin que, por el mero hecho de que estas cuestiones tengan que ver, en todo o en parte, con normas de interés general como sería la legalidad de los actos administrativos o el orden público, sea un obstáculo para acudir al arbitraje.

En efecto, desde hace algunos años, la arbitrabilidad se ha expandido de una manera significativa, pudiendo, ahora, considerarse como arbitrables una gran gama de materias que antes no lo eran. La posición actual respecto a la arbitrabilidad es que la misma está tan abierta y aceptada, que debe ser considerada como la regla y no como la excepción, permitiendo a los árbitros conocer sobre los diferentes temas puestos bajo su competencia, bajo el control del Poder Judicial en caso que una de las partes en la disputa considere que los árbitros han fallado en su deber de aplicar las normas legales o de haberlas aplicado de forma tal que se vea afectado el interés general.

\subsection{De la arbitrabilidad de los actos administrativos}

Ahora, la problemática pasa a la arbitrabilidad de los actos administrativos emitidos por la Administración en uso o no de sus facultades exorbitantes, derivados de los contratos administrativos dentro de los cuales existe o se ha pactado una cláusula arbitral. 
Desde hace algunos años existe un gran debate respecto a definir si los mismos serían o no materia arbitrable. Existen al menos tres tendencias claramente marcadas en cuanto a la arbitrabilidad de los actos administrativos: la primera, que radicaliza la posición de la no arbitrabilidad; la segunda, que establece que únicamente serían arbitrables las controversias contractuales de las cuales tenga efectos económicos o patrimoniales para las partes, siendo en definitiva lo arbitrable el efecto económico o patrimonial de los actos administrativos contractuales; $y$, la tercera, que asegura la arbitrabilidad de los actos administrativos, inclusive su legalidad y validez.

Repasemos, brevemente, a las dos primeras, para luego pasar a la que nos interesa en el presente trabajo.

Ha sido una práctica común que los defensores de los Estados planteen la no arbitrabilidad de los actos administrativos, lo que retrasa o demora el tratamiento del fondo; planteamientos que son buenos en caso de haber dudas razonables, caso contrario es deplorable. El argumento típico sostiene que la revisión de los actos administrativos, fuera de la propia Administración, está reservada, per se, a la jurisdicción judicial contencioso-administrativa $^{14}$.

El profesor NEIRA ha expuesto con claridad las razones para limitar la competencia de los árbitros en las controversias contractuales en las que es parte la Administración:

Cuando en el objeto de la litis de una acción arbitral se encuentran entretejidos aspectos de naturaleza contractual y otros relativos al control de legalidad de las actuaciones del Estado [... ] los árbitros están llamados a aceptar su competencia para resolver las diferencias de orden contractual [...] pero no aceptar lo que queda fuera de la jurisdicción convencional, es decir, los aspectos de control de constitucionalidad o de legalidad de actos administrativos o de actos normativos ${ }^{15}$.

14. H. Díaz-Candia, El Correcto Funcionamiento Expansivo del Arbitraje, Con Especial Referencia a la Aceptación del Arbitraje Contencioso-Administrativo, 1ra. Ed., Arazandi, 2001. p. 44. 
Este criterio también ha sido replicado en un caso de arbitraje nacional. En el caso Andinatel vs. Secretaría Nacional de Telecomunicaciones, el Tribunal Arbitral estableció como su competencia resolver sobre la controversia surgida en relación con el contrato, negándose a

juzgar la legalidad de actos administrativos expedidos por el Consejo Nacional de Telecomunicaciones y cualquier otro aspecto que conforme los Arts. 1 y 2 de la Ley de la Jurisdicción Contencioso Administrativa pudieren corresponder a la jurisdicción legal ejercida por los Tribunales Distritales de esa materia $^{16}$.

Criterio que también fue acogido por el Presidente de la Corte Provincial de Justicia de Pichincha, quien al resolver una acción de nulidad contra un laudo arbitral señaló lo siguiente:

El Tribunal de Arbitraje de la Cámara de Comercio de Quito [...] no podía en forma alguna, ni por pedido de parte, ni de oficio, entrar a examinar y discutir y peor aún declarar la legitimidad o ilegitimidad contenida en un acto de la administración pública pues, como ha quedado dicho, esta facultad no es en forma alguna, ni siquiera por excepción, materia transigible, por ello la discusión de la legitimidad de los actos de la administración pública, por mandato legal queda reservada exclusivamente para la jurisdicción ${ }^{17}$.

15. E. Neira Orellana, "El Estado y el Juicio de Arbitraje Según la Legislación Ecuatoriana”, El Arbitraje en el Perú y el Mundo, 1ra. Ed., 2008, p. 57. El profesor MoRALES mantiene la misma posición: "aunque se trate de un acto administrativo que ha nacido dentro del ámbito de la relación contractual, la determinación de su legalidad o no, es de exclusiva competencia de los Tribunales Contencioso Administrativos"; M. MoRALEs, "Complejidad del arbitraje local cuando una de las partes pertenece al sector público", Análisis y actualidad del Derecho Administrativo, Universidad Andina Simón Bolívar-Instituto de Estudios de Derecho Administrativo y Social, 2014, p. 379.

16. Tribunal Arbitral del Centro de Arbitraje y Mediación de la Cámara de Comercio de Quito. Laudo en Arbitraje. Caso No. 010-06, 30/10/2007. Este criterio fue replicado en otro caso en el cual el Tribunal arbitral señaló que no tenía competencia "para resolver nada en relación a los actos administrativos que pudieren haberse dictado respecto de esta relación contractual"; Tribunal Arbitral del Centro de Arbitraje y Mediación de la Cámara de Comercio de Quito. Constructora Carlos Poggi Barbieri S.A. v. Ministerio de Desarrollo Urbano y Vivienda, Laudo en Arbitraje, Caso. No. 02-10, 05/05/2011.

17. Corte Provincial de Justicia de Pichincha, Di-Chem Del Ecuador v. Petroindustrial, Sentencia, Caso No. 41-2009-B.L, 22/03/2010; Centro de Arbitraje y Mediación de la Cámara de Comercio de Quito, Acción de nulidad del laudo arbitral, Caso No, 045-05, 22/03/2010. 
Este argumento tiene su fundamento en el artículo 173 de la CRE ${ }^{18}$ y legal en el artículo 217 del Código Orgánico de la Función Judicial ${ }^{19}$ y artículo 10 de la Ley de la Jurisdicción Contencioso Administrativa ${ }^{20}$, los cuales establecen que la no arbitrabilidad de los actos administrativos se basa, principalmente, en que la legalidad o validez del acto administrativo escapa de la esfera de lo transigible y por tanto de lo arbitrable, y que la CRE y la ley establece como única vía para la impugnación de los actos administrativos a la Función Judicial, específicamente, a los jueces de lo contencioso administrativo.

Entonces, resulta que la transigibilidad de la legalidad del acto administrativo sería el fundamento primario de este argumento, del cual profundizaremos más adelante.

En cuanto a la segunda corriente que establece que solo las controversias contractuales con efectos económicos para las partes podrían ser arbitrables, esta resultaría ser una solución ecléctica, que goza de mucha aceptación, dada la presunción de la legalidad que da ejecutividad al acto administrativo, por la cual sería solo un juez ordinario quien pueda desaparecer del mundo jurídico el acto administrativo. Por lo que los árbitros deberán limitar su examen y competencia a los aspectos meramente económicos o patrimoniales que se deriven de dichos actos administrativos.

18. CRE. Art. 173.- Los actos administrativos de cualquier autoridad del Estado podrán ser impugnados tanto en la vía administrativa como ante los órganos de la Función Judicial.

19. Código Orgánico de la Función Judicial, RO Sup. No. 544, 9/03/2009. Art 217.- ATRIBUCIONES Y DEBERES.- Corresponde a las juezas y jueces que integren las salas de lo contencioso administrativo: 1. Conocer y resolver las controversias que se suscitaren entre la administración pública y los particulares por violación de las normas legales o de derechos individuales, ya en actos normativos inferiores a la ley, ya en actos o hechos administrativos, siempre que tales actos o hechos no tuvieren carácter tributario; 2. Supervisar la legalidad de los actos y hechos administrativos, y la potestad reglamentaria de la Administración no tributaria, como también las acciones judiciales que se incoen por su inactividad $[\ldots]$.

20. Ley de la Jurisdicción Contencioso Administrativa, RO No. 338, 18/03/1968. Art. 10.- Son atribuciones y deberes jurisdiccionales del Tribunal de lo Contencioso - Administrativo: a) Conocer y resolver en única instancia de las impugnaciones a los reglamentos, actos y resoluciones de la Administración Pública, o de las personas semipúblicas o de derecho privado con finalidad social o pública y decidir acerca de su legalidad o ilegalidad;[...]. 
En esta teoría observamos que tiene una condición, la cual implica que para que la Administración pueda someterse a arbitraje, esta utilice la figura del contrato, figura del Derecho Privado por excelencia, renunciando de esta manera a la imposición unilateral de su voluntad para lograr sus objetivos en acuerdo con los particulares y actuando a través de actos administrativos contractuales que resultarían arbitrables, únicamente, en cuanto a los efectos patrimoniales de los mismos. A esta posición la denominaremos en adelante como la de los "efectos patrimoniales".
Al respecto el tratadista BIELSA manifiesta que:
[L]a conveniencia del arbitraje en ciertas cuestiones, aún de la administración pública, es evidente. Ninguna incompatibili- dad puede alegarse respecto del arbitraje en el derecho admi- nistrativo tratándose de cuestiones puramente patrimoniales sobre las cuales puede haber transacción o renuncia. En el ar- bitraje se trata de examinar no la legitimidad de los actos ad- ministrativos sino y tan solo consecuencias patrimoniales ${ }^{21}$.

Este criterio fue asumido en el Ecuador en un caso de arbitraje en el Centro de Arbitraje y Mediación de la Cámara de Comercio de Quito, del cual el profesor NeIRA destaca lo siguiente:

Este precedente plantea que cuando el objeto de la Litis de una acción arbitral se encuentren entretejidos aspectos de naturaleza contractual y otros relativos al control de legalidad de las actuaciones del Estado, la tutela efectiva de derechos que impone la Constitución a todos los órganos que administran justicia (artículo 24 numeral 17), -árbitros incluidos-, impide a éstos declarase incompetentes sin más. Los árbitros están llamados a aceptar su competencia para resolver las diferencias de orden contractual y a continuar el juicio arbitral exclusivamente sobre estos temas, pero a no aceptar lo que queda fuera de la jurisdicción convencional, es decir, los aspectos de control de constitucionalidad o de legalidad de actos administrativos o de los actos normativos ${ }^{22}$.

21. R. Bielsa, Derecho Administrativo, Tomo V, 6ta. Ed., 1980, p. 687.

22. E. Neira Orellana, N. 15, p. 426. 
Es evidente que el tribunal asumió esta posición de los efectos patrimoniales, por la cual, se declaró competente únicamente para tratar las diferencias de carácter contractual, con un efecto patrimonial sobre las partes, excluyendo de su competencia el control de legalidad sobre la validez de los actos administrativos de la Administración derivados de dicha relación contractual.

El Consejo de Estado Colombiano también se ha pronunciado en la misma forma:

[S]i bien es factible que las partes de un contrato en donde una de ellas sea una entidad del estado, pueden convenir en someter a la decisión de árbitros las controversias que entre ellas surjan por situaciones de hecho derivadas del desarrollo o ejecución de dicho contrato, en modo alguno puede predicarse lo mismo respecto de la definición de la legalidad o ilegalidad de los actos administrativos que la entidad contratante expida con motivo de la celebración y ejecución del contrato, por cuanto las diferencias que el contratista pueda tener acerca del contenido y los efectos de este tipo de actos no son ni pueden ser, objeto de transacción y, por ende tampoco de arbitramento, dado que en ello está comprometido el orden jurídico y el ejercicio del poder público, materias éstas que, en modo alguno están sujetas a la disposición de las partes ${ }^{23}$.

No me parece que esta sea una solución completa al tema de la arbitrabilidad de las controversias contractuales de las que el Estado es parte, principalmente por tres razones:

La primera, es que en muchas, por no decir todas las ocasiones, el tribunal arbitral, inclusive para determinar los aspectos patrimoniales de la disputa, debería analizar y pronunciarse respecto de la validez y eficacia del acto administrativo que ha afectado a la relación contractual. Desde mi punto de vista, mal haría un tribunal arbitral en hacer una determinación de carácter pa-

23. Sala de lo Contencioso Administrativo. Caso Empresa de Transporte Masivo del Valle de Aburra, Sec. 3ra., 23/02/2000. C, reproducido en M. GonZÁLEZ, El contencioso contractual, Universidad Libre de Colombia. 2004. p. 317. Citado por J. Agullar AndRADE, "Sobre las Materias Arbitrables en el Derecho Administrativo", Revista Ecuatoriana de Arbitraje, No. 1, 2009, p. 29. 
trimonial que esté en contra de lo establecido en un acto administrativo, ya que, implícita o tácitamente, lo estaría dejando sin efecto, afectando sin duda a su validez y a la presunción de legalidad de la que goza, por lo que, cualquier decisión que adopte el tribunal arbitral en este sentido, sería nula o fácilmente anulable.

La segunda razón sería que, tal como claramente lo describe el profesor AgUILAR, dentro de una relación contractual en la cual se ha originado una controversia entre las partes, misma que tendría efectos económicos sobre ellas, sería muy fácil para la Administración emitir todos los actos administrativos necesarios para blindar tal situación y así convertir en no arbitrable a la disputa, inclusive en sus efectos patrimoniales ${ }^{24}$.

Y la tercera, es que esta vía obligaría a las partes a litigar la misma controversia ante dos jurisdicciones diferentes: ante los jueces de lo contencioso administrativo en cuanto a la legalidad de los actos administrativos materia de la controversia; $y$, ante los árbitros los efectos patrimoniales derivados de dichos actos administrativos, cayendo, inclusive, en un posible problema de prejudicialidad, rompiendo con el principio de unidad jurisdiccional consagrado en la legislación ${ }^{25}$. Esto, además conllevaría, igualmente, un incumplimiento al convenio arbitral pactado entre las partes.

Entonces, pasemos a abordar la tercera corriente de pensamiento respecto de la arbitrabilidad, misma que establece la posibilidad cierta de que la legalidad de los actos administrativos pueda ser sometida a arbitraje.

Esta corriente tiene dos teorías que funcionan como pilares fundamentales sobre los que sustenta su existencia y aceptación, los cuales se encuentran íntimamente ligadas la una con la otra:

24. J. Aguilar Andrade, Arbitrabilidad de Actos Administrativos, Tesis Magistral, Universidad San Francisco de Quito, Quito, 2014. pp. 45 y ss.

25. CRE, Art. 76 y 172, RO No. 449. 20/10/2008; Código Orgánico de la Función Judicial. Art. 7. RO No. Sup. 544, 9/03/2009. 
La primera es la naturaleza contractual de la relación en la cual se encuentra inmiscuida la Administración, por lo que la arbitrabilidad de los actos administrativos efectuados por la administración tiene su razón de ser en su "voluntad" de someterse al contrato y, por ende, al método de solución de controversias en él establecido, que en este caso sería el arbitraje.

Como complemento necesario a la anterior se encuentra la segunda teoría de sustento de la arbitrabilidad, la cual tiene que ver con que a la Administración se le ha atribuido la facultad legal de acudir al arbitraje dentro de sus relaciones contractuales; por lo que, al ser la ley la que le otorga la facultad a la Administración para pactar arbitraje, los actos administrativos por ella producidos serían arbitrables.

Empecemos por el tema contractual. Ya había mencionado que al recurrir la Administración a la figura legal del contrato para lograr los intereses comunes, esta renuncia a su facultad de imponer unilateralmente su voluntad, asociándose con los privados para lograr dicho objetivo, con lo cual, al estar en el campo de lo contractual, estaríamos, a su vez, en el campo de lo transigible y, por ende, de lo arbitrable.

De acuerdo con esta teoría, hablamos de que el arbitraje es admisible para anular actos administrativos cuando las partes en una relación contractual, siendo una de ellas la Administración que emite los actos administrativos, así lo han acordado y pactado, de manera clara e inequívoca, en la respectiva cláusula arbitral, en aplicación de los principios generales del Derecho como es la buena fe contractual y el pacta sunt servanda. Entonces, resulta que el consentimiento sería la clave para que el arbitraje tenga competencia. Consentimiento que, necesariamente, de acuerdo con mi criterio, debe encontrar su razón de ser en la ley.

Al respecto, GARCÍA DE ENTERRÍA y FERNÁNDEZ señalan que "la legalidad atribuye potestades a la administración, precisamente. La legalidad otorga facultades de actuación, definiendo 
cuidadosamente sus límites, apodera, habilita a la administración para su acción confiriéndole al efecto poderes jurídicos" ${ }^{26}$. Entonces, es claro que la administración ejerce las potestades que la ley le confiere, y nada más.

BULLARD, quien, después de hacer una excelente distinción de los actos del Estado que estarían bajo el iuri imperii y los que estarían bajo el ius gestionis ${ }^{27}$, dice lo siguiente:

Esta claro entonces que los actos del Estado de naturaleza comercial son plenamente arbitrables. Asunto superado. Respecto de los actos del Estado inherentes al mismo por caer bajo el velo del ius imperium, la regla es que si el Estado consintió explícitamente al arbitraje no puede liberarse del mismo, entendiéndose el pacto como una renuncia a cualquier restricción a la arbitrabilidad del conflicto ${ }^{28}$.

Además, menciona el mismo autor que:

[...]debemos tomar en cuenta que el Derecho de los diferentes Estados, tiene como fuentes principales a los principios generales del Derecho, dentro de los cuales se enmarca el principio de la buena fe contractual o el mismísimo pacta sunt servanda, mediante los cuales, por el simple hecho de que el Estado haya pactado o convenido válidamente el arbitraje para que tenga que ser respetado, aun inclusive para actos de ius imperium que en principio no podrían someterse al mismo ${ }^{29}$.

La posibilidad de que el Estado acuda al arbitraje tiene carácter constitucional ${ }^{30}$. Años antes la misma LAM ya había establecido esta posibilidad ${ }^{31}$. Tanto la CRE como la LAM le otorgan a la Administración la potestad de someterse a arbitraje.

26. E. García de Enterría, y T. Fernández, Curso de Derecho Administrativo, 12da. Ed., Tomo I, Temis S.A., 2008. p. 423.

27. A. Bullard, "Enemigos Íntimos. El Arbitraje y los Contratos Administrativos", Revista Peruana de Arbitraje, No. 2, 2006. pp. 175-180.

28. Ídem, p. 187.

29. Ídem, p. 201.

30. El artículo 190 de la CRE dice "En la contratación pública procederá el arbitraje en derecho, previo pronunciamiento favorable de la Procuraduría General del Estado, conforme a las condiciones establecidas en la ley." 
Al existir esta potestad legal resultaría lógico concluir que existe la posibilidad de arbitrar el tema de la controversia sin más limitaciones que la misma ley pueda establecer. Tal como lo señala el profesor AGUILAR: "[...]conferida una potestad no hay que buscar en ella límite alguno; es la ley que regula la potestad, la que debe expresamente excluir determinados asuntos de su ejercicio y, si no lo hace, no pueden considerarse excluidos" ${ }^{\prime \prime 2}$.

Esto nos lleva a concluir que, la potestad de someter a arbitraje incluye a todos los temas relacionados a dicha relación contractual; y si la misma ley no ha establecido un límite para la arbitrabilidad de los actos administrativos, entonces los mismos serían arbitrables.

Siendo esto así, en esta situación, nos encontraríamos en el ámbito del ejercicio de las potestades estatales. Mientras en el Derecho Privado se recurre al arbitraje en ejercicio de la autonomía de la voluntad, siendo la ley la que pone límites a este ejercicio de libertad, en el Derecho Público la competencia para recurrir al arbitraje se entrega como un todo, al que no hay que buscar más límites que los que consten en la propia norma ${ }^{33}$.

La anterior referencia que hace el profesor AGUILAR tiene que ver con la visión que dentro del Derecho Privado se le ha sido asignada a la arbitrabilidad como una limitación a la autonomía de la voluntad, mientras que en el Derecho Público, este límite no existiría si el mismo no se encuentra en la propia norma legal.

31. El artículo 4 de la LAM dice: "Para que las diferentes entidades que conforman el sector público puedan someterse al arbitraje, además de cumplir con los requisitos que establece esta Ley, tendrán que cumplir los siguientes requisitos adicionales: a) Pactar un convenio arbitral, con anterioridad al surgimiento de la controversia; en caso de que se quisiera firmar el convenio una vez surgida la controversia, deberá consultarse al Procurador General del Estado, dictamen que será de obligatorio cumplimiento; b) La relación jurídica a la cual se refiere el convenio deberá ser de carácter contractual; c) En el convenio arbitral deberá incluirse la forma de selección de los árbitros; y, d) El convenio arbitral, por medio del cual la institución del sector público renuncia a la jurisdicción ordinaria, deberá ser firmado por la persona autorizada para contratar a nombre de dicha institución. El incumplimiento de los requisitos señalados acarreará la nulidad del convenio arbitral."

32. J. Aguilar Andrade, N. 24, p. 71 (2014).

33. Ibídem. 
Muchos podrían atacar este criterio invocando el artículo 1 de la LAM que hace mención a las materias transigibles, sin embargo, este argumento es rebatible, tal como lo vamos a revisar con detenimiento más adelante.

Además, en el momento en el que existe una norma que permite el arbitraje en materias relacionadas con el Derecho Público, y el Estado ha pactado expresamente arbitraje, sí cabría dicho arbitraje, ya que ha sido el propio Estado quien ha decidido establecer la posibilidad de someterla a arbitraje, en aplicación de una potestad legalmente otorgada.

Revisando nuevamente tanto la norma constitucional como la legal, vemos que no existe límite alguno con referencia a los contratos administrativos ni a los actos administrativos derivados de dicha relación contractual.

Recurrir a lo establecido en el artículo 173 de la CRE no serviría de límite para la arbitrabilidad. Explico porqué.

El mencionado artículo establece que "los actos administrativos de cualquier autoridad del Estado podrán ser impugnados tanto en la vía administrativa como ante los órganos de la Función Judicial." Al encontrarse los artículos 173 y 190 en el mismo nivel constitucional, considero que ninguno prevalece por sobre el otro. Qué quiero decir: el artículo 173 establece, la que podríamos considerar como la regla general en cuanto a que los actos administrativos podrán ser impugnados por la vía administrativa o por la vía judicial, cubriendo así a la generalidad de los actos administrativos.

No obstante lo anterior, el artículo 190 complementa al 173 en cuanto a los actos administrativos contractuales, incluyendo, según nuestro criterio, a los actos administrativos que sin ser estrictamente contractuales, tendrían relación con el contrato. Este artículo establece, claramente, la posibilidad de arbitrar en la contratación pública, sin establecer ningún límite específico para la legalidad de los actos administrativos. 
Por lo tanto, en caso de que en una relación contractual con el Estado en la que no se haya pactado arbitraje, los actos administrativos contractuales, podrían ser impugnados tanto en la vía administrativa como por la vía judicial; pero, si las partes han pactado arbitraje, estos pueden ser impugnados dentro del arbitraje, sin limitación alguna, salvo las propias limitaciones establecidas en la ley y en el convenio arbitral.

También podríamos decir que, al incluir la referencia a la contratación pública en la norma constitucional, se abrió la posibilidad de arbitrar los actos administrativos contractuales o relacionados con la relación contractual, manteniendo al artículo 173 para el resto de actos administrativos.

Un ejemplo de esta teoría es el artículo 10 de la Ley de Hidrocarburos ${ }^{34}$, el cual empieza, de manera general, señalando que los actos administrativos emitidos por las entidades de dicho sector podrán ser impugnados por la vía administrativa aplicando el Estatuto del Régimen Jurídico Administrativo de la Función Ejecutiva (ERJAFE), o por la vía judicial aplicando la Ley de la Jurisdicción Contencioso Administrativo; para después establecer la posibilidad de acudir al arbitraje para resolver las posibles disputas que sucedan dentro de los contratos suscritos al amparo de esa ley, de acuerdo con el convenio arbitral correspondiente, sin que se haya excluido de esta vía a los actos administrativos.

Si la CRE no limita a la arbitrabilidad de los actos administrativos, mal lo podría hacer una norma de nivel inferior como el Código Orgánico de la Función Judicial y la Ley de la Jurisdicción Contencioso Administrativa. Más bien consideramos que lo que hacen estos cuerpos normativos, es implementar lo constitucio-

34. Ley de Hidrocarburos. Art. 10. RO No. 711, 15/11/1978. Los actos jurídicos de las instituciones del sector podrán ser impugnados en sede administrativa o judicial. La impugnación en sede administrativa se hará de conformidad con el Estatuto del Régimen Jurídico Administrativo de la Función Ejecutiva. En sede judicial, se tramitará ante los tribunales distritales de lo Contencioso - Administrativo. Las controversias que se deriven de los contratos regidos por esta ley podrán ser resueltas mediante la aplicación de sistemas de mediación y arbitraje de conformidad con lo establecido en la ley y en el convenio arbitral correspondiente. 
nalmente establecido por el artículo 173 en caso de que las partes decidan ir por la vía judicial para impugnar al acto administrativo contractual, siendo, entonces el tribunal de lo contencioso administrativo, y no otros -como por ejemplo los jueces civiles- los competentes para conocer la controversia. Lo mismo sucedería en caso del ERJAFE, si las partes decidiesen ir por la vía administrativa.

Lo mismo sucede con el artículo 4 de la LAM que es el que establece lo que la Administración debe cumplir para someterse a arbitraje, siendo lo establecido en el literal $b$ ) respecto a que la relación debe ser contractual, el único límite impuesto a la Administración.

Entonces, en palabras del profesor AgUILAR:

Cuando el arbitraje involucra a un ente público, los árbitros no están ligados por el mandato que surja de la voluntad autónoma de quienes pactaron el arbitraje, sino que se someten a los expresos mandatos legales sobre la materia que se somete a su conocimiento. Esto quiere decir que, en estos casos, un árbitro no evalúa temas renunciables sino que, como lo haría un juez contencioso administrativo, analiza la situación desde el punto de vista de la legalidad ${ }^{35}$.

Tan cierta es la arbitrabilidad de los actos administrativos, que en la legislación ecuatoriana existen varias normas legales que otorgan la potestad legal a la Administración para acudir al arbitraje, en los casos en los que la Administración tiene la potestad para contratar, sin que en ellas se limite el uso del arbitraje para el control de la legalidad de los actos administrativos.

La Ley Orgánica del Sistema Nacional de Contratación Pública (LOSNCP), que es la norma reina de la contratación pública, otorga la potestad a la Administración de someter a arbitraje disputas originadas de los contratos sometidos a dicha ley ${ }^{36}$. Es más, esta ley va más allá al establecer, específicamente, la posibilidad 
Arbitrabilidad de Actos

Administrativos Contractuales

de acudir al arbitraje en las controversias originadas, por ejemplo, en la imposición de multas o la terminación unilateral de contra$\operatorname{tos}^{37}$, todas ellas implementadas por intermedio de actos administrativos.

Resulta obvio que los reclamos de los contratistas, solo pueden referirse a actos administrativos, lo que nos lleva a la conclusión de que es posible arbitrar la legalidad de dichos actos administrativos.

Pero esa no es la única ley ecuatoriana que permite el arbitraje para los actos administrativos. Por ejemplo, ya mencionamos lo que dice la Ley de Hidrocarburos, la cual, siendo una ley muy importante en el Ecuador, establece la posibilidad de someter a arbitraje las posibles disputas relacionadas con los contratos regidos por esa ley, sin que establezca ningún limite de arbitrabilidad de los actos administrativos ${ }^{38}$.

Otra ley que incluye esta posibilidad para recurrir al arbitraje es la Ley de Modernización. Sobre la misma la jurisprudencia se ha pronunciado de manera clara, de la siguiente manera:

36. Ley Orgánica del Sistema Nacional de Contratación Pública, Art. 104, RO Sup. No. 395, 4/08/2008. Métodos Alternativos de Solución de Controversias.- De existir diferencias entre las partes contratantes no solventadas dentro del proceso de ejecución, podrán utilizar los procesos de mediación y arbitraje en derecho, que lleven a solucionar sus diferencias, de conformidad con la cláusula compromisoria respectiva.

37. Ídem, Art. 71. Cláusulas Obligatorias.- En los contratos sometidos a esta Ley se estipulará obligatoriamente cláusulas de multas, así como una relacionada con el plazo en que la entidad deberá proceder al pago del anticipo, en caso de haberlo; el que no podrá exceder del término de treinta (30) días. Las multas se impondrán por retardo en la ejecución de las obligaciones contractuales conforme al cronograma valorado, así como por incumplimientos de las demás obligaciones contractuales, las que se determinarán en relación directa con el monto total del contrato y por cada día de retraso. Las multas impuestas al contratista pueden ser impugnadas en sede administrativa, a través de los respectivos recursos, o en sede judicial o arbitral. (las cursivas me pertenecen). Art. 95. Notificación y Trámite.[...] Si el contratista no justificare la mora o no remediare el incumplimiento, en el término concedido, la Entidad Contratante podrá dar por terminado unilateralmente el contrato, mediante resolución de la máxima autoridad de la Entidad Contratante, que se comunicará por escrito al contratista y se publicará en el portal institucional del Servicio Nacional de Contratación Pública SERCOP. La resolución de terminación unilateral no se suspenderá por la interposición de reclamos o recursos administrativos, demandas contencioso administrativas, arbitrales o de cualquier tipo o de acciones de amparo de parte del contratista[...]" (las cursivas me pertenecen).

38. Ley de Hidrocarburos, RO No. 711, 15/11/1978, Art. 10. 
Los reclamos en vía judicial de los contratos administrativos, en cuanto al control de legalidad y al cumplimiento de sus estipulaciones, es propia del recurso o acción de lo contencioso administrativo, materia especializada, propia de la competencia privativa de la Jurisdicción Contencioso Administrativa; la misma que nace de la relación de derecho material, que reconoce expresamente el legislador. Consecuentemente la acción de nulidad del contrato administrativo no corresponde a la competencia ordinaria civil, aunque se invoquen normas legales sustantivas que rigen el contrato de naturaleza civil, ya que hacer lo contrario es inobservar por falta de aplicación los artículos 1, 3 y 10 de la Ley de la Jurisdicción Contencioso Administrativa, que regulan ese tipo de litigios, en concordancia con el artículo 1 inciso 2 del Código de Procedimiento Civil. En resumen, el artículo 38 (r) de la Ley de Modernización del Estado, dispone imperativamente, que los tribunales distritales de lo Contencioso Administrativo "conocerán y resolverán" de todas las demandas, sin distinción alguna, salvo los reclamos sometidos a mediación y arbitraje, que se refieran a contratos administrativos, entre ellos, por tanto, los de concesión de servicios, o concesión de uso de bienes públicos; sin que esto, suceda en la especie ${ }^{39}$ (las cursivas me pertenecen).

Pero existe otra opinión en la que la misma Corte Suprema del Ecuador, es aún más clara y explícita en cuanto a la posibilidad de arbitraje de los actos administrativos:

Por estas razones en más de una oportunidad, como en el presente caso, establecido que la jurisdicción contencioso administrativa tiene competencia privativa y excluyente, excepto en lo relativo a los procedimientos arbitrales, respecto de la contratación pública y mas aun, de todas las controversias derivadas de actos, hechos, contratos y reglamentos solo producidos o celebrados por las instituciones públicas, esta Sala admitió, como en el presente caso, la procedencia del recurso de un auto inhibitorio expedido por los tribunales inferiores ${ }^{40}$ (las cursivas me pertenecen).

39. Corte Suprema de Justicia, Segunda Sala de lo Civil y Mercantil, Contraloría General del Estado-Municipalidad de Cuenca y Autoparque S.A., Caso No. 59-2003, RO No. 9, 06/06/2003.

40. Corte Suprema de Justicia, Sala de lo Contencioso Administrativo, Gaceta Judicial 1, Serie XVIII, $18 / 10 / 2004$. 
Lo mismo ha sucedido con los tribunales arbitrales que se han pronunciado favorablemente respecto a la posibilidad de que sean ellos mismos quienes decidan sobre la legalidad de actos administrativos, los cuales han anulado actos administrativos de imposición de multas ${ }^{41} \mathrm{o}$ se han pronunciado sobre la legalidad de declaratorias de terminación unilateral de contratos ${ }^{42}$.

En otro caso de arbitraje en la Cámara de Comercio de Quito entre el Consorcio E-VOTE y el Tribunal Supremo Electoral en el año 2007, se descartó la excepción de que de la terminación unilateral del Estado no era materia arbitral. El árbitro único rechazó la excepción, se declaró competente y fallo a favor del Estado, razonando que el Trámite de terminación unilateral y anticipada del contrato estuvo apegado a la Ley y al contrato ${ }^{43}$.

Existe un último criterio que nos faltaría por revisar, con el cual reforzaríamos nuestra tesis sobre la arbitrabilidad de los actos administrativos, es el principio pro arbitri.

Con la evolución del arbitraje y su aceptación constitucional, también se ha desarrollado el denominado principio pro arbitri, el mismo que, palabras más palabras menos, sería el principio por el cual todos los actores jurídicos, incluidos los jueces ordinarios, deben realizar interpretaciones que favorezcan, impulsen y otorguen validez y eficacia al arbitraje.

\section{En palabras del profesor NEIRA:}

41. Tribunal Arbitral del Centro de Arbitraje y Conciliación de la Cámara de Comercio de Guayaquil, APLITEC S.A. v. Empresa Cantonal de Agua Potable y Alcantarillado de Guayaquil, Laudo en Arbitraje, Caso No. 022-03, 21/07/2004; Tribunal Arbitral del Centro de Arbitraje y Conciliación de la Cámara de Comercio de Guayaquil, BIVA International S.A. y Bureau Veritas Inspectio Valuation Assessment and Control, BIVAC B.V. v. Corporación Aduanera Ecuatoriana, Laudo en el Arbitraje, Caso No.027-03, 15/09/2004.

42. Tribunal Arbitral del Centro de Arbitraje y Mediación de la Cámara de Comercio de Quito, Fondo de Inversión Social de Emergencia v. CEPLAES. Laudo en Arbitral. Caso No.077-09, 06/07/2011;Tribunal Arbitral del Centro Nacional de Mediación y Arbitraje de la Cámara de la Construcción de Quito, Consorcio Ingenieros Pérez Coloma v. Ministerio de Obras Públicas. Laudo en Arbitraje, Caso No. 0092005, 6/04/2007.

43. E. Pérez CAmacho, Derecho Administrativo, 3ra. Ed., Tomo II, Corporación de Estudios y Publicaciones, 2009. p. 980. 
El principio pro arbitraje que inspira al sistema ecuatoriano y que está consagrado en varias normas de la LAM, (artículos 5 inciso 3, 6, 7 inciso 2 y 35), impone a los árbitros y a los jueces hacer efectiva la voluntad de las partes cuando ha sido manifiesta para someter sus controversias al juicio de árbitros, independientemente del error de derecho en que aquellas hubieren podido incurrir al estipular que el laudo sea en equidad. En este caso el mandato legal que impone el arbitraje en derecho prevalece sobre el acuerdo de voluntades sin viciar de nulidad la cláusula arbitral ${ }^{44}$.

Este principio también ha sido considerado como un blindaje para el arbitraje frente a la jurisdicción ordinaria. Sin embargo, la aplicación de este principio tampoco puede ser absoluto, ya que el mismo arbitraje permite la intervención judicial para determinados temas, intervención que debería, idealmente, ser mínima y limitada, exclusivamente a proteger derechos fundamentales de las personas.

Además, este principio implicaría que, al haber pactado arbitraje dentro de un contrato en el cual la Administración es una de las partes, los árbitros, y si es del caso los jueces, deberán respetar dicho acuerdo arbitral y, si en el mismo no se ha establecido un límite a la arbitrabilidad de los actos administrativos de la Administración, los árbitros y jueces no deberían imponer ningún límite y, mas bien, en aplicación de este principio, deberían favorecer al arbitraje incluido para dichos actos administrativos.

La Corte Constitucional, dentro de un proceso de acción extraordinaria de protección, se pronunció de manera clara aplicando el principio pro arbitraje:

Una vez que, [...] se configuró un convenio arbitral con todos sus efectos, la justicia ordinaria estaba impedida, por no tener jurisdicción ni competencia para este caso, de conocerlo y resolverlo. Pues bien, como a pesar de este impedimento, tanto el Juez Tercero de lo Civil de Pichincha, la Primera Sala de lo Civil de la ex Corte Superior de Justicia de Pichincha, hoy 44. E. Neira Orellana, N. 1. p. 427. 
Corte Provincial de Justicia, y la Segunda Sala de lo Civil de la ex Corte Suprema de Justicia, hoy Corte Nacional de Justicia, fallaron en el caso en mención, atribuyéndose una competencia que no tenían, vulneraron claramente el derecho del accionante al debido proceso en lo que respecta a ser juzgado por un juez o autoridad competente, con observancia del trámite propio de cada procedimiento ${ }^{45}$.

En conclusión podemos decir que, los actos administrativos emitidos por la Administración relativos a un contrato administrativo en el cual se ha pactado arbitraje, los mismos sí serían arbitrables, fundamentados en que la arbitrabilidad de estos actos administrativos nace de una potestad otorgada por la ley, la misma que es ejercida por la Administración al momento que conviene o pacta arbitraje. El límite a la arbitrabilidad de los actos administrativos, únicamente, podría encontrarse o en la misma ley que establece la posibilidad de que la Administración pacte arbitraje o en el convenio arbitral por ella suscrito; por lo que, en caso de no haberse establecido dicho límite, los actos administrativos, inclusive su legalidad sería arbitrable.

Con base en lo anterior podemos decir que los tribunales arbitrales están obligados a respetar el principio de legalidad en cuanto a la posibilidad de arbitrar los actos administrativos, así como también están obligados a respetar la presunción de legalidad de los actos administrativos; y que, por tanto, la jurisdicción contencioso administrativa, no es exclusiva para realizar el control de legalidad de los actos administrativos.

45. Corte Constitucional. Cobo v. Misle Zaidan. Citado por Jara Vásquez, María Elena, Caso No. $172-$ 09-EP, Sentencia 0006-10-SEP-CC, RO Sup. No. 159, 26/04/2010; "Decisiones de la Justicia Estatal Ecuatoriana Sobre Arbitraje. Un Análisis Desde la Perspectiva del Principio Favor Arbitralis”, Revista Ecuatoriana de Arbitraje, No. 4, 2012, pp. 168-169. 


\section{DE LA TRANSIGIBILIDAD EN EL DERECHO ADMINISTRATIVO}

Como vimos en la sección anterior, tanto la CRE como la LAM, después de proclamar la aceptación y validez del sistema arbitral en el Ecuador y de definir al arbitraje, señalan que el mismo se enmarca para resolver controversias susceptibles de transacción, sean estas presentes o futuras, sirviendo, entonces, como un límite para el arbitraje.

El artículo 2348 del Código Civil define a la transacción como "un contrato en que las partes terminan extrajudicialmente un litigio pendiente, o precaven un litigio eventual. No es transacción el acto que sólo consiste en la renuncia de un derecho que no se disputa."

La jurisprudencia ecuatoriana ha dicho lo siguiente respecto de la transacción:

Por la transacción se hace el abandono de una pretensión o de un derecho que se creía tener, y ella importa, por esto, una disposición o una enajenación de este derecho; y, por otra parte, no puede transigir sino la persona capaz de disponer de los objetivos comprendidos en la transacción; de aquí que, para transigir a nombre de otra persona sea necesario su poder especial, con indicación de los bienes, derechos y acciones sobre que debe versar la transacción; pues, de otra suerte, habría de resultar que el mandatario pudiera usar a voluntad de la facultad para transigir, y también a voluntad disponer de los bienes y derechos de su mandante; lo cual es inaceptable $^{46}$.

Entonces, tomando las palabras de ANDRADE CEVAlLos, concluimos que:

46. Gaceta Judicial, Año XIX, Serie IV, No. 42, Quito. 24/06/1920. p. 336. Citado por M. ANDRADE CEVALLOS, N. 13, p. 207. 
Por lo expuesto, podríamos resumir que el objeto de una transacción puede incluir todos los asuntos que están en el comercio, que son de libre disposición de las personas, es decir, se puede transigir sobre todos los objetos y derechos que la persona puede libremente disponer. [...] Se puede transigir sobre todas aquellas cosas que están en el comercio, que son objeto del derecho de dominio (cosas corporales e incorporales) las personas que pueden transigir son sus propietarios: personas naturales o jurídicas, personas de derecho privado o público ${ }^{47}$.

Como lo hemos visto, la transigibilidad es una figura legal que nace y vive en el Derecho Privado, ya que estamos hablando de disposición de derechos individuales y de la voluntad de su titular para, libremente, disponer de ellos. Entonces, la transigibilidad vendría a constituirse en una especie de límite a esta libertad para disponer de los derechos de los particulares.

En contraposición a esto estaría la irrenunciabilidad de los derechos, con el objetivo de evitar que dichos derechos individuales y la voluntad de su titular no ofenda o traspase los derechos comunes de la sociedad o el llamado bien común de la sociedad.

Es por esto que no podemos desconocer que la transigibilidad es un elemento presente en el arbitraje, motivo por el cual, debemos repasar su incidencia en el mismo y, sobre todo, en el arbitraje administrativo.

Para empezar, tenemos que, necesariamente, hablar de requisitos de validez procesal del arbitraje, siendo la transigibilidad de la materia de la disputa uno de ellos, tal como lo establece el mencionado artículo 1 de la LAM. La disputa sometida a los árbitros, tanto así como el derecho controvertido que da origen a la disputa, ha de ser susceptible de transacción. 
Al respecto, veamos lo que DíAZ-CANDIA nos dice:

Para el arbitraje no es esencial que las partes renuncien a derechos, excepto el que se refiere a accionar ante los tribunales judiciales lo que han convenido en someter a arbitraje. Tampoco es esencial para el arbitraje que se repartan bienes, derechos o intereses entre las partes, de manera que ninguna resulte totalmente vencida ${ }^{48}$.

En efecto, lo importante no viene a ser, necesariamente, que los derechos en disputa sean transigibles, sino más bien que la disputa sea transigible. Ciertamente, creo que el enfoque debe estar en la voluntad de las partes de someter dicha disputa al arbitraje. Someterse a arbitraje no implica de por sí, que uno va a disponer o renunciar irreversiblemente un derecho, ya que no es lo mismo que sea transigible a que sea renunciable; simplemente se lo va a litigar, que es diferente, con la obvia consecuencia de que lo puede perder en beneficio de otro que antes de la disputa no lo tenía. Entonces, sería la disputa sobre un derecho la que tiene que ser considerada como transigible o no, para que pueda ser sometida a arbitraje.

Una vez que se abrió la puerta del arbitraje para las disputas relacionadas a contratos administrativos, la doctrina transpoló los mismos requisitos del arbitraje entre privados para el arbitraje con el Estado, resultando esto en que se tenía que observar el tema de la transigibilidad en dichos arbitrajes, o sea la relación de esta con el Derecho Administrativo. En palabras del profesor NeIRA $^{49}$, el requisito de la transigibilidad también le es aplicable al Estado.

Era claro entonces que, para desarrollar un proceso arbitral es requisito indispensable que la materia sobre la cual verse el conflicto debe ser transigible y en esa línea, la doctrina empezó

48. H. Díaz-CANDia, N. 14, p. 27.

49. [E]1 Art. 1 de la Ley de Arbitraje y Mediación prevé que podrán someterse a la jurisdicción convencional ejercida por árbitros las controversias susceptibles de transacción. Y éste que es requisito de validez para toda clase de controversias arbitrales, lo es también para aquellas en que el Estado sea parte; E. Neira Orellana, N. 15, p. 421. 
por tratar de resolver la siguiente pregunta: ¿La declaratoria sobre la legalidad o ilegalidad de un acto administrativo se circunscribe dentro de lo que se determina como materia transigible?

El mismo profesor NEIRA señala lo siguiente:

Como regla de general aplicación en el ámbito del Derecho Público, no son transigibles las potestades que el orden jurídico reconoce a la administración pública y a las demás funciones del Estado para el cumplimiento de sus fines. Por tanto, no podrán ser objeto de transacción ni de litigio en un proceso arbitral el ejercicio de las potestades normativa, resolutiva, determinadora, recaudadora, sancionadora, ni la potestad pública constitucionalmente establecida para administrar el sistema electoral, legislar y juzgar, ejercer el patrocinio público, investigar delitos, controlar los bienes y recursos del Estado, o de precautelar su integridad interna y externa. Lo anterior revela una vinculación muy estrecha entre la transigibilidad del derecho como exigencia de carácter general aplicable a todas las controversias sometidas al juicio de árbitros (artículo 1 de la LAM), y el requisito de que la relación jurídica que será objeto de juzgamiento arbitral, en juicios en que sea parte el Estado, tenga naturaleza contractual (artículo 4 literal b) de la LAM) ${ }^{50}$.

Esta corriente de pensamiento nos dice que las facultades de la administración, así como sus actuaciones no serían susceptibles de ser sometidas a arbitraje, ya que las mismas no son transigibles desde ningún punto de vista.

Sin embargo, habría una excepción a las relaciones contractuales en las que participa el Estado, las cuales sí podrían ser materia de juicio de árbitros. Tal como lo señala el profesor NeIRA, de acuerdo con LAM, la relación entre la transigibilidad y la materia contractual de la relación estarían ligadas en la consideración para someter a arbitraje una determinada actuación estatal, siendo así que, solo las actuaciones del Estado dentro de relaciones contractuales, serían capaces de ser sometidas a arbitraje. 
Esta también es la opinión de MONTES De ECHEVERRI, quien al analizar la posición que la jurisprudencia colombiana ha adoptado sobre la materia, comenta:

[...] ]es claro que la actuación de la Administración dentro de una relación contractual tiene una naturaleza distinta a aquella que cumple cuando actúa en función de imperio. En este caso, tiene un comportamiento similar al del particular dentro de la relación contractual, aun cuando tenga prerrogativas especiales. Así, según mi opinión, todas las manifestaciones de voluntad de la Administración en un contrato estatal pueden ser analizadas y juzgadas por el juez arbitral ${ }^{51}$.

Sin embargo, a pesar de que ya se ha establecido que la Administración goza de la facultad para suscribir contratos administrativos, inclusive estableciendo en el mismo la posibilidad de uso de prerrogativas que lo pondrían en superioridad al contratista privado, el tema de la transigibilidad había sido un tema que no pudo ser sorteado con facilidad para que la Administración pueda pactar arbitraje y, sobre todo, que sus actos administrativos puedan ser impugnados en arbitraje.

Producto de esta discusión dio nacimiento, por ejemplo, a la teoría de la arbitrabilidad de los efectos patrimoniales de los actos administrativos, tal como lo revisamos anteriormente; o, la teoría de la arbitrabilidad únicamente de los actos administrativos discrecionales pero no de los actos administrativos reglados, llegando, igualmente a la conclusión de que todos los actos administrativos, inclusive los discrecionales están sometidos a la legalidad y por tanto no serían transigibles, ergo, arbitrables ${ }^{52}$.

$Y$, a pesar de que algunos criterios se han emitido al respecto, considero que el profesor AgUILAR, es quien ha brindado la respuesta más adecuada al problema de la transigibilidad de los actos administrativos en el arbitraje.

51. S. Montes de Echeverri, "La solución de controversias contractuales por la vía arbitral", Revista de Derecho Público, No. 14, Universidad de Los Andes, 2002, p. 141. Citado por J. Aguilar AndRAde,

"Sobre las Materias Arbitrables en el Derecho Administrativo", Revista Ecuatoriana de Arbitraje, No. 1, 2009, p. 29.

52. E. Salcedo Verduga, "El Arbitraje: La Justicia Alternativa.” 1ra. Ed., 2001. p. 37. 
Magistralmente, el profesor AGUILAR ha desarrollado el tema y ha expresado, en conclusión, que en el Derecho Administrativo no hay cabida para el concepto de la transigibilidad. Al establecer la ley, la competencia o facultad de la Administración Pública de acudir al arbitraje, la transigibilidad no tiene cabida ${ }^{53}$, por lo que sus actos administrativos serían plenamente arbitrables ${ }^{54}$.

Dice el profesor Aguilar que la Administración no actúa sobre la base del principio de libre disponibilidad de derecho, sino mas bien que actúa sometida al principio de legalidad, pudiendo hacer únicamente lo que el ordenamiento jurídico le dispone ${ }^{55}$, tal como lo revisamos en la sección anterior.

Si la Administración no actúa en el plano de las libertades, sino en el plano de la legalidad, exclusivamente, donde los derechos no son libremente disponibles, el concepto de la transigibilidad como límite al ejercicio de la libertad, pierde todo sentido, por lo que, en el ámbito del Derecho Administrativo no sería aplicable el concepto de la transigibilidad como requisito para la arbitrabilidad, mas bien, la posibilidad de arbitrar los actos administrativos se trataría del cumplimiento de potestades legalmente establecidas en la ley ${ }^{56}$.

Entonces, en el arbitraje administrativo, el límite a su arbitrabilidad, incluida la arbitrabilidad de los actos administrativos, no estaría limitada por la transigibilidad como requisito sine qua non para su validez, sino que sería el principio de legalidad su requisito indispensable, siendo entendido esto, tal como lo revisamos en el capítulo anterior, que la ley le haya otorgado la potestad de acudir al arbitraje para revisar la legalidad de los actos administrativos, sin más limites que los propios establecidos en la misma ley.

Por lo tanto, sin libertad de por medio, no hay que preguntarse qué es aquello sobre lo cuál esa libertad no puede ejercerse

53. J. Aguilar Andrade, N. 24, p. 67 (2014).

54. Ídem, p. 74.

55. Ídem, p. 68.

56. Ídem,. p. 69 
y, por lo tanto, la idea de transigibilidad carece de sentido en el arbitraje administrativo ${ }^{57}$.

BULLARD ha expresado algo parecido:

Sin duda uno puede decir que la facultad de dictar y hacer cumplir leyes no es de libre disposición. Quién podría dudarlo. Pero si la Ley lo autoriza, esa facultad puede ser arbitrable, no porque no sea de libre disposición, sino porque el marco legal autoriza su arbitrabilidad. No se debe por tanto confundir que las leyes no sean de libre disposición con el hecho de que las consecuencias contractuales de esas leyes no sean arbitrables ${ }^{58}$.

Atando esto a lo mencionado en la anterior respecto a la arbitrabilidad de los actos administrativos tenemos que, en Ecuador sí existen normas legales que otorgan esta competencia de acudir al arbitraje para resolver las disputas que podrían sucederse al amparo de dichos cuerpos normativos, sin que en los mismos se hayan establecidos límites a dicha arbitrabilidad, por lo que, esta arbitrabilidad sería absoluta, incluyendo la posibilidad de revisar la legalidad de los actos administrativos derivados de dichas relaciones con particulares.

Recordemos, por ejemplo, lo mencionado con respecto a la LOSNCP o la Ley de Hidrocarburos, en las cuales se confiere al Estado la competencia para convenir arbitraje para resolver las posibles disputas que podrían suceder dentro de los contratos celebrados con contratistas particulares al amparo de dichas leyes. Estas normas no han establecido límite alguno respecto a la arbitrabilidad de los actos administrativos emitidos dentro de dichos contratos, por lo que no cabría, entonces, buscar más límites a esta arbitrabilidad.

La conclusión a la que llega el profesor AgUiLAR, con la cual compartimos, es completamente satisfactoria para el tema de la

57. Ídem, p. 71.

58. A. Bullard GonzÁlez, "El Estado Soy Yo. Arbitraje y Regulación: ¿Son los Árbitros los Nuevos Reguladores?", Revista Ecuatoriana de Arbitraje, No. 4, 2012, p. 321. 
arbitrabilidad de los actos administrativos, desde todo punto de vista:

(i) ratifica la teoría apoyada en este trabajo de que la arbitrabilidad de los actos administrativos depende de las competencias que la misma ley le otorga a la Administración, si la ley le concede la facultad para suscribir acuerdos arbitrales, entonces, la Administración así lo puede hacer;

(ii) resuelve de manera incontrovertida el tema de la transigibilidad con relación al Derecho Administrativo, al determinar que dicha institución del Derecho Privado no tiene cabida en el Derecho Público, por lo que no puede ser asumido como un requisito para la arbitrabilidad de los actos administrativos; $\mathrm{y}$,

(iii) en Derecho Administrativo, no habrían más límites a la arbitrabilidad que los propios límites establecidos en la propia ley, por lo que si esta no establece ningún límite, sobre todo para la arbitrabilidad de los actos administrativos, entonces no cabría que se establezcan otros límites ajenos a dicha ley.

\section{De la ARBITRABILIDAd DE lOS ACTOS ADMINISTRA- TIVOS EN EL DERECHO COMPARADO Y EN EL ARBI- TRAJE INTERNACIONAL}

Una vez que hemos llegado a la conclusión de que los actos administrativos emanados de la Administración relacionados con los contratos que suscribe para la consecución de sus objetivos, serían plenamente arbitrables, inclusive su legalidad, es necesario que revisemos cual ha sido el desarrollo de este tema, tanto en las legislaciones internas de otros países, así como también dentro del arbitraje internacional. 


\subsection{En el derecho comparado}

En Colombia, el desarrollo del tema ha sido poco favorable hacia la arbitrabilidad de los actos administrativos. Con base en los pronunciamientos del Consejo de Estado, este país ha optado, principalmente, por la tesis de los efectos patrimoniales.

[...]la legalidad de los actos administrativos no es transigible y, por tanto, no puede someterse a decisión de los árbitros; pero por el contrario, las causas y los efectos patrimoniales de los actos administrativos podrán someterse a decisión del juez arbitral siempre y cuando la controversia no sea consecuencia directa de la legalidad del acto administrativo del cual se deriva y que los actos administrativos que sirvan de fundamento a la acción no hayan sido dictados en uso de los poderes excepcionales de la Administración ${ }^{59}$.

En Venezuela, ha sido la doctrina quien se ha pronunciado de manera favorable en el tema de la arbitrabilidad de los actos administrativos.

En arbitraje interno de los contratos administrativos, se debe entender que si se puede arbitrar la anulación de los actos administrativos, salvo expresa exclusión en la misma cláusula arbitral. [...] incluso para la anulación de actos administrativos, es aceptable que la voluntad de las partes, aunada a la voluntad de la ley, implique la sustracción de la jurisdicción judicial, siempre y cuando se asegure que la voluntad de las partes sea expresada de manera verdaderamente libre, o al menos con conocimiento de causa y suficiente advertencia ${ }^{60}$. [...] Se establece que un árbitro puede anular un acto administrativo de igual manera como lo puede hacer un juez. [...] La jurisdicción de los árbitros para analizar la legalidad de los actos administrativos deviene del consentimiento otorgado

59. D. Posse, "Restricciones a las entidades estatales colombianas para acudir al arbitraje internacional", F. Mantilla (Coor.), en Arbitraje internacional, Tensiones actuales, 2007. p. 15. El autor resume el contenido de una sentencia del Consejo de Estado Colombiano de 8 de junio de 2000 (exp. 16973). Para profundizar este tema en Colombia véase M. IBAGÓN, Los actos administrativos contractuales proferidos en virtud de poderes excepcionales y el arbitraje en Colombia, Serie de Derecho Administrativo, No. 16, 2012.

60. H. DíAZ-CANDia, N. 1, pp. 108-110. 
por la Administración. Hay que tener en cuenta la separabilidad de los actos administrativos con el contrato administrativo como tal, más aun si contiene la cláusula arbitral y si esta cubriría o no a esos actos administrativos. La no inclusión debería limitarse a los actos administrativos precontractuales. Los actos administrativos integrantes del contrato deben considerarse dentro del ámbito de la cláusula arbitral tomando en cuenta la amplitud de la misma ${ }^{61}$.

De la misma manera, en el Perú, el profesor BULLARD ha dicho lo siguiente:

Lo importante es entonces tener en cuenta que, si la ley autoriza la arbitrabilidad de materias que en principio no son de libre disposición, esa autorización hace que las materias sean arbitrables. Y en el caso de muchos de los países de la región, el marco legal autoriza a que dicha arbitrabilidad sea posible, con las particularidades que puedan presentarse en cada uno de estos ordenamientos ${ }^{62}$.

En los Estados Unidos de América, ha sido su Corte Suprema de Justicia, quien desde hace ya varias décadas, se ha pronunciado favorablemente respecto de la arbitrabilidad, diciendo que la existencia de una norma dentro de una materia considerada como de "orden público" que regule la cuestión a decidir, no impide, per se, que los árbitros conozcan de ella. Y, a pesar de haber también establecido que no toda materia puede ser arbitrable, ha señalado que la arbitrabilidad sería la regla y, por ende, la no-arbitrabilidad la excepcional, debiendo esta ser interpretada restrictivamente, debiendo aplicarse solo en temas que claramente han sido determinadas como no arbitrables ${ }^{63}$.

Según esta distinguida Corte, la resolución al tema de la arbitrabilidad se encontraría en la propia ley que permita o no el

61. Ídem, pp. 148-149.

62. A. Bullard GonZÁlez, N. 58, pp. 331-332.

63. U.S. Supreme Court, 13/05/1991, in re Gilmer v. Interstate/Johnson Lance Corp., 500 U.U. 20. U.S. Supreme Court, 8/06/1987, in re Shearson/American Express Inc. v. McMahon, 482 U.S. 220. U.S. Supreme Court, 11/12/2000, in re Green Tree Financial Corp. Alabama et al. v. Randolph, No. 991235, 531 U.S. 79. Citado por R. CAIVANO, N. 1, p. 358 (2008). 
sometimiento al arbitraje de determinada cuestión y la determinación que deban realizar los propios árbitros respecto a su capacidad para decidir la materia a ellos sometida (principio kompetenz-kompetenz).

Es así como, con una evidente tendencia pro arbitraje, esta Corte Suprema ha declarado como arbitrables las controversias que involucran derechos contenidos en normas imperativas que se creían reservadas para los jueces estatales como eran las normas de transacciones bursátiles ${ }^{64}$, de competencia $(\text { Antitrust })^{65} \mathrm{y}$ de daños punitivos (punitive damages) ${ }^{66}$.

\subsection{En el arbitraje internacional}

En el ámbito del arbitraje internacional, sea este comercial o de inversiones, el tema de la arbitrabilidad de actos administrativos ha sido amplia y favorablemente acogido.

Partiendo del hecho cierto del ostensible crecimiento y desarrollo de las inversiones extranjeras, principalmente en los países en vías de desarrollo sobre todo dentro de los ámbitos de los servicios públicos y de los denominados sectores estratégicos, los inversionistas buscaron herramientas efectivas para la protección de sus inversiones.

Una de estas fue sin duda el arbitraje, con el objetivo de encontrar un foro neutral para la solución de las posibles controversias que se podían suscitar con los países receptores de dichas inversiones, sin necesidad de recurrir a las cortes locales. Fue así como los Estados empezaron a aceptar esta jurisdicción arbitral dentro de las relaciones contractuales entabladas con los inversionistas extranjeros.

64. U.S. Supreme Court, Shearson /American Express Inc. v. McMahon, 482 U.S. 220 (1987). Citado por R. CAIVANo, "Planteos de Inconstitucionalidad, N. 6, pp. 124-125 (2006).

65. U.S. Supreme Court, Mitsubishi Motors v. Soler Chrysler-Plymouth, Inc; 473 U.S. 614 (1985).

66. U.S. Supreme Court, Mastrobuono v. Shearson Lehman Hutton, Inc., 514 U.S. 52 (1995). 
Como lo señala CRAIG, PARK y PAULSSON refiriéndose al arbitraje internacional:

El arbitraje comercial internacional es usualmente el único proceso adjudicatorio aceptable para ambas partes en los contratos con el Estado. El Estado buscará arbitraje para evadir la publicidad, o evitar someterse a la Corte de un país extranjero que aparecería como una afrenta a su soberanía. La empresa multinacional puede temer que las Cortes del país anfitrión sean influenciadas indebidamente por su gobierno, o que sin una sumisión al arbitraje podría no haber certeza de la renuncia a la soberanía del Estado ${ }^{67}$.

De esta manera, los Estados evitaban el tener que someterse a jurisdicciones de otros países y los inversionistas encontraron una vía confiable a la cual acudir en caso de disputas con el Estado receptor de su inversión. En este marco, el arbitraje resultó ser el método idóneo, ya que es un tercero, privado, imparcial quien tendría la tarea de decidir sobre una disputa, con la suficiente independencia como para obrar de una o otra manera, sin verse afectado por posibles presiones o influencias por parte de los altos mandos estatales, o verse afectado por parcializaciones que podrían ocurrir en otros foros.

Tanta fue la aceptación del arbitraje, que los Estados desde hace varios años atrás han suscrito tratados internacionales dentro de los cuales se ha establecido como método de solución de controversias al arbitraje.

Los claros ejemplos de estos tratados son los famosos Tratados Bilaterales de Promoción y Protección Recíproca de Inversiones (TBI), en los cuales se han establecido como posibles vías de solución el sometimiento al Centro Internacional para el Arreglo de Disputas sobre Inversiones (CIADI) o a procedimientos arbitrales Ad-Hoc bajo las Reglas de Arbitraje de la Comisión de las

67. Traducción libre. L. Craig, W. Park, W. William y J. Paulsson, International Chamber of Commerce Arbitration, 3ra. Ed., New York. Ocean Publication Inc. p. 661. Citado por A. Bullard GonZÁlez, N. 27, p. 168-169 (2006). 
Naciones Unidas para el Derecho Mercantil Internacional (CNUDMI), dentro de los cuales un inversionista que se sienta afectado por un acto del Estado pudiere reclamar la responsabilidad de dicho Estado siguiendo estos procesos.

Producto de esto es que tenemos que dentro de estos arbitrajes internacionales, se ha admitido la posibilidad de arbitrar no solo los contratos administrativos por los cuales se han instrumentado estas inversiones, sino también, los actos administrativos por los cuales la Administración Estatal ha actuado dentro de dicha relación contractual.

Varios han sido los tribunales de arbitraje que han discutido y aceptado, sin limitación, la arbitrabilidad de los actos administrativos en cuanto a su validez y eficacia. Un ejemplo reciente y muy renombrado es el caso de la compañía petrolera norteamericana Occidental en contra de la República del Ecuador en donde se discutió sobre la arbitrabilidad del decreto de caducidad, el cual, obviamente, se trataba de un acto administrativo ${ }^{68}$.

Tal como lo podemos apreciar de los razonamientos señalados anteriormente, el desarrollo internacional, doctrinario y jurisprudencial de la arbitrabilidad ha sido siempre, extraordinariamente, a favor del arbitraje, eliminando en gran medida la posibilidad de alegar la no arbitrabilidad de asuntos que tengan que ver con normas de carácter imperativo o de plano con normas de orden público, permitiendo que los árbitros tengan la facultad de conocerlos y decidir sobre ellos, dentro de los cuales podríamos incluir a los actos administrativos contractuales emitidos por los Estados.

68. ICSID, Occidental Petroleum Corporation and Occidental Exploration and Production Company v. The Republic of Ecuador, Laudo, Case No. ARB/06/11, 05/10/2012. Disponible en $<$ http://goo.gl/1Po5CO $>$. También se pueden varios otros casos en los cuales decretos de caducidad fueron conocidos, discutidos por tribunales de arbitraje. Véase ICSID, Burlington Resources Inc. v. $\square$ The Republic of Ecuador. Decisión on Liability. Case No. ARB/08/5, 14/12/2012, disponible en: $<\mathrm{http}$ :/goo.gl/TI1nk9>. Véase, ICSID, Perenco Ecuador Limited v. The Republic of Ecuador, Decision on Remaining Issues of Jurisdiction and on Liability, Case No. ARB/08/6, 12/09/2014, disponible en: $<$ http://goo.gl/he2bZP $>$. 
Internacionalmente, este argumento también encuentra su razón de ser en los principios generales del Derecho. Tal como lo mencionamos anteriormente en el ámbito del arbitraje nacional, la arbitrabilidad, dentro del arbitraje internacional, también encuentra su sustento en los principios de buena fe contractual y pacta sunt servanda, principios rectores y fundamentales del derecho internacional.

Sobre este particular MONTOYA ha señalado:

[...]una vez que el Estado o sus administraciones públicas han suscrito una cláusula de arbitraje, se han comprometido con carácter internacional y en forma irrevocable ${ }^{69}$.

De la misma manera, Delaume comparte esta opinión:

[...]Un número impresionante de precedentes indican que tales prácticas tienen pocas posibilidades de ser exitosas. Incluso en casos en los que se demostró que no se siguieron todos los procedimientos previstos bajo la Ley del propio Estado, los tribunales arbitrales, de manera consistente han sostenido que el Estado involucrado tienen un deber en buena fe de revelar la situación a la otra parte y que la omisión en hacerlo impide al Estado para posteriormente cuestionar la invalidez de su compromiso ${ }^{70}$.

Por último, el mismo BULLARD al respecto también nos dice "el Estado no puede contradecir sus propios actos y, por tanto, queda sometido a la voluntad expresada, sin perjuicio del análisis de su legitimidad a la luz de la legislación doméstica ${ }^{71 "}$.

En conclusión, en cuanto a la arbitrabilidad de los actos administrativos dentro del ámbito del arbitraje internacional, no ha quedado duda alguna que los actos administrativos del Estado pueden ser arbitrables, en consideración a principios generales

69. U. Montoya Alberti, El Arbitraje Comercial, 1988. p. 72.

70. Traducción libre. G. Delaume, "The Finality of Arbitration Involving States: Recent Developments", Arbitration International, 1989, Vol. 5(1), p. 26.

71. Ibídem. 
del Derecho como son la buena fe contractual y el pacta sunt servanda que prevalecerían por sobre cualquier tipo de legislación nacional que se oponga a dicha arbitrabilidad.

\section{CONCLUSIONES}

La arbitrabilidad se ha expandido de una manera significativa, pudiendo, ahora, considerarse como arbitrables una gran gama de materias que antes no lo eran. La posición actual respecto a la arbitrabilidad es que la misma está tan abierta y aceptada, que debe ser considerada como la regla y no como la excepción, permitiendo a los árbitros conocer sobre los diferentes temas puestos bajo su competencia, bajo el control del Poder Judicial en caso que una de las partes en la disputa considere que los árbitros han fallado en su deber de aplicar las normas legales o de haberlas aplicado de forma tal que se vea afectado el interés general.

La CRE, la LAM, LOSNCP, entre otras identificadas a lo largo del texto, han sido las que han otorgado al Estado la facultad para acudir a arbitraje. Entonces, podemos decir que: sí existe una norma que, expresamente, permite al Estado acudir al arbitraje para solucionar las disputas que surjan con sus contratistas, lo normal será que ellas sean aptas para hacerlo sin obstáculo alguno, además de los límites impuestos por la propia ley y el convenio arbitral, y que sea el tribunal arbitral quien decida su propia competencia con relación a las disputas a ellos sometidas (con base en el principio kompetenz-kompetenz), sin que, por el mero hecho de que estas cuestiones sometidas a ellos tengan que ver, en todo o en parte, con normas de interés general como sería, por ejemplo, la legalidad de los actos administrativos, sea un límite para acudir al arbitraje.

Esto nos llevó a concluir que los actos administrativos emitidos por la Administración relativos a un contrato administrativo en el cual se ha pactado arbitraje, sí serían arbitrables, fundamen- 
tados en que la arbitrabilidad de los mismos nace del ejercicio de una potestad otorgada por la ley, la misma que es ejercida por la Administración al momento en que conviene o pacta arbitraje. El límite a la arbitrabilidad de los actos administrativos, únicamente, podría encontrarse o en la misma ley que establece la potestad para que la Administración pacte arbitraje o en el convenio arbitral por ella suscrito; por lo que, en caso de no haberse establecido dicho límite, los actos administrativos, incluyendo su legalidad sería arbitrable.

Con base en lo anterior también podemos concluir que los árbitros están obligados a respetar el principio de legalidad en cuanto a la posibilidad de arbitrar los actos administrativos, así como también están facultados a revisar la legalidad de los actos administrativos; y que, por tanto, la jurisdicción contencioso administrativa, no es exclusiva para realizar el control de legalidad de los actos administrativos.

Al referirnos al tema de la transigibilidad como un límite a la arbitrabilidad, hemos dicho que, en el arbitraje administrativo, el límite a arbitrabilidad de la legalidad de los actos administrativos, no estaría limitada por la transigibilidad como requisito sine qua non para su validez, sino que, sería el principio de legalidad su requisito indispensable, siendo entendido esto, que la ley le haya otorgado la potestad al Estado para acudir al arbitraje, haya o no, incluido un límite para revisar la legalidad de los actos administrativos. Por lo que, el concepto de transigibilidad, como límite a la autonomía de la voluntad, tal como ha sido concedida en el Derecho Privado, carece de sentido en el Derecho Administrativo y, principalmente, en el arbitraje administrativo. 